\title{
Sensory Marketing in the Quality of Service of the Hotel El Libertador in the City of Riobamba
}

\section{Marketing Sensorial en la Calidad del Servi- cio del Hotel el Libertador de la Ciudad de Riobamba}

\section{Diana Carolina García Mayorga*, Jorge Antonio Vasco Vasco, Juan Carlos Montufar Guevara}

VII International Congress of

Science, Technology,

Entrepreneurship and

Innovation (SECTEI 2020)

Corresponding Author:

Diana Carolina García

Mayorga

dianisdg1811@gmail.com

Published: 26 August 2021

Production and Hosting by

Knowledge E

(ㄷ) Diana Carolina García Mayorga et al. This article is distributed under the terms of the Creative Commons

Attribution License, which permits unrestricted use and redistribution provided that the original author and source are credited.
S OPEN ACCESS
Grupo de Investigación Innova MKT, Facultad de Administración de Empresas, Escuela Superior Politécnica de Chimborazo, Riobamba, Ecuador

\section{Abstract}

This research aimed to improve the perception of the quality of service of the Hotel El Libertador by means of sensory marketing elements to improve the tourist experience. The study variables were derived from the visual, auditory and kinesthetic perceptions related to the quality of service. In addition, an analysis was performed with the EEG MindWave Mobile 2 biometric equipment, to understand the levels of attention, meditation and blinking. In terms of visual perception, it was determined that attention should be paid to the clothing of the staff $(27.6 \%)$ and signage (40.9\%). The elements of the auditory perception of the hotel had low ratings because the hotel has not implemented elements of auditory sensory marketing in the facilities. Four of the seven elements of the kinesthetic perceptions were not attended and had a weight between $38.3 \%$ and $46.7 \%$. As a result of these analyses, a sensory marketing proposal was suggested, which included visual, auditory and kinesthetic marketing strategies, to provide a solution to the existing problems with the hotel facilities. Based on the biometric equipment results, a proposal was made for sensory marketing strategies with elements of experiential communication to be used in the hotel's facilities which would also improve the perception of service quality.

Keywords: sensory marketing, perception, tourism, senses, quality of service, neuromarketing.

\section{Resumen}

La investigación tuvo como objetivo mejorar la percepción en la calidad de servicio del HOTEL EL LIBERTADOR, por medio de elementos de marketing sensorial mejorando la experiencia del turista. La investigación es de tipo correlacional, las variables de estudio se desprenden de la percepción visual, auditiva y kinestésica relacionada con la variable calidad del servicio, además se realizó un análisis con equipo biométrico EEG MindWave Mobile 2 en las instalaciones de la empresa para identificar los niveles de atención, meditación y parpadeo. En los elementos de percepción visual se determinó que se debe prestar atención a la vestimenta del personal que tiene un $27,6 \%$ y la señalética $40,9 \%$. Los elementos de la percepción auditiva del hotel tienen una baja calificación porque el hotel no ha implementado elementos de marketing sensorial auditivo en las instalaciones, 4 de los 7 elementos de la percepción kinestésica no han sido atendidos y tienen una ponderación entre 38,3\% a 46,7\% Por medio de este análisis se planteó una propuesta de marketing sensorial para dar solución a la problemática existente en las instalaciones del hotel, la misma que contiene estrategias de marketing visual, auditivo y kinestésico. Mediante la obtención de resultados y análisis 
realizados con equipos biométricos, se pudo determinar estrategias de marketing sensorial con elementos de comunicación experiencial en las instalaciones de la empresa hotelera que permita mejorar la percepción de la calidad de servicio.

Palabras Clave: marketing sensorial, percepción, turísmo, sentidos, calidad de servicio, neuromarketing.

\section{Introducción}

El objetivo principal de la investigación es mejorar la percepción de la calidad del servicio en el Hotel el Libertador de la ciudad de Riobamba.

Se ha considerado investigar la situación del Hotel el Libertador porque se ha identificado que existe una baja percepción por parte de los turistas que visitan las instalaciones, la empresa hotelera únicamente se enfoca en dar un servicio y no crear lazos futuros con los clientes, es por esta razón que se identificó que dentro del hotel no existe una experiencia de impacto a través de los sentidos que permita que el cliente retorne, tome la decisión de volver a adquirir el servicio y la experiencia sea una opción de futuro cuando visiten la ciudad de Riobamba.

La percepción que los turistas tienen al momento de ingresar a un punto de venta es de vital importancia para la empresa, porque depende del servicio que brindan para que la rentabilidad aumente o disminuya. Lo que se espera con la mejora de la percepción de la calidad de servicio del Hotel el Libertador es crear lazos de relaciones futuras con los clientes y fidelizar la marca.

'El Marketing es el proceso de planificación y ejecución de la concepción, fijación del precio, promoción y distribución de ideas, bienes y servicios para crear intercambios que satisfagan los objetivos de los individuos y de las organizaciones' [1].

El ser humano es entendido como un receptor de percepciones que utiliza los cinco sentidos, y gracias al poder que posee el cerebro, genera una actitud. La finalidad del marketing sensorial consiste en crear la identidad completa en la marca. Las acciones tradicionales del marketing iban dirigidas al sentido de la vista y del oído, pero el marketing sensorial abarca el resto de los sentidos: Olfato, gusto y tacto [2].

'El marketing sensorial es una nueva área del marketing que tiene como objetivo la gestión de la comunicación de la marca hacia los cinco sentidos del consumidor con el fin de afectar a su imagen e influir sobre su comportamiento de compra en relación a un producto o servicio' [3]. 
Los sentidos y las relaciones con los clientes buscan aumentar la eficacia de la comunicación con las asociaciones de la marca y maximizar la experiencia de compra del consumidor.

El marketing sensorial debe generar una experiencia sensorial. Es importante generar estímulos en cada uno de los cinco sentidos de los clientes con el objetivo de generar una reacción en sensaciones y percepciones [4].

\subsection{Marketing visual}

'El marketing visual es un conjunto de técnicas y elementos que se aplican en una tienda para poner los productos a disposición del consumidor obteniendo rentabilidad, seduciéndolo a la compra'. Como estrategia de marketing se toma la técnica de marketing psicológica influyendo en aspectos de colores, decoración, colocación del producto [5].

\subsection{Marketing auditivo}

Se enfoca en el tipo de música que puede ser aplicada en una tienda con el fin de influir en el proceso de decisión de compra, a más de eso crea experiencia de compra en el consumidor. A la hora de aplicar música en los establecimientos es importante analizar el tipo de tienda, consumidor y música adecuada. La música también incrementa las ventas en el punto de venta.

\subsection{Marketing kinestésico}

Engloba todo lo que se percibe por el tacto, gusto y el olfato. Es una de las técnicas más utilizadas en el mundo de las compras. Se da cuando una persona ingresa a un supermercado y pasa por la sección de panadería y huele a pan recién hecho, o cuando al acudir al cine y al entrar huele a palomitas. No se trata de que estén recién hechas, sino que el ambientador que usan es con olor a palomitas [6].

\subsection{Marketing sensorial en el punto de venta}

Relación de los sentidos y acciones incluidos en el marketing sensorial del punto de venta:

El marketing sensorial en el punto de venta consiste en la correcta utilización de la ambientación de los elementos de la tienda, con el fin de trabajar sobre los sentidos del consumidor para generar reacciones cognitivas de comportamiento que sean parte de la creación de fidelización y a la estimulación de compra que lo lleven a realizar 


\section{Table 1}

Relación de los sentidos.

Vista
Tacto
Olfato
Oído
Gusto

Colores utilizados en la decoración ambiental

-lluminación utilizada

-Arquitectura interior

-Ambientes temporales creados

-Exposición de los artículos propios

-Materiales utilizados

-Temperatura y humedad de la tienda

-Accesibilidad a producto

-Aromas de ambiente global

-Aromas de ambientes específicos

-Aromas de productos

-Música ambiental

-Ruido generado en tienda

-Sonido de los propios productos

-Degustaciones de productos en punto de venta

- Comidas y bebidas servidas en servicios de tienda

-Venta de productos para su consumo fuera de la tienda

Fuente: Referencia [3].

la compra y que vuelva a comprar de esta manera creando relaciones futuras entre la empresa y el cliente.

Cada empresa integra elementos sensoriales propios relacionados a sus productos o servicios generando de forma natural comunicación e información sensorial que provocan entre empresa y cliente percepciones y expectativas.

\subsection{Los Sentidos, la experiencia primaria}

Los sentidos son funciones que permiten al ser humano percibir el mundo exterior por sí mismo, por esta razón cada uno de los sentidos posee un órgano físico, es así que los órganos de los sentidos están preparados para captar información; ya que actúan de manera conjunta, para propiciar en la persona un adecuado conocimiento de lo que le rodea y adquirir su propia experiencia [7].

El sentido visual detecta estímulos luminosos, es la capacidad de distinguir los objetos y su entorno. Este órgano capta las vibraciones de la luz, que se desplaza de forma onda y que vibra en contacto con los distintos cuerpos, transmitiéndolas al cerebro. Las vibraciones producidas por la luz atraviesan la córnea, penetran en la pupila, son ajustadas por el cristalino y se reflejan en la retina. De ahí el nervio óptico transmite la transformación al encéfalo, es un área de la corteza cerebral llamada tálamo. Además de la forma y el color del objeto, el cerebro capta también la distancia, el tamaño, la movilidad y el grado de definición de la imagen [8]. 
El sentido auditivo transforma las variaciones de presión originadas por la propagación de las ondas sonoras en el aire, hay sonidos que llevan mentalmente a determinados lugares, como es el caso del sonido de las olas. Pero también el sonido produce sensación de tranquilidad o de relax. La música afecta a los estados de ánimo y a la generación de recuerdos a largo plazo, produciendo emociones, sentimientos y experiencias en los clientes.

El olfato es el sentido de mayor permanencia en la memoria humana, influyendo mucho en las decisiones de comprar. Hace que el consumidor viaje a la nostalgia y al recuerdo de buenos momentos. Es difícil acertar que un gran número de clientes, pero se puede crear un aroma personificado, algo suave y que sea capaz de transmitir comodidad, tranquilidad, relajación y seguridad. Los olores crean sensaciones, aunque en ciertos casos pueden resultar desagradables.

El sentido del tacto favorece a la identidad de la marca. Incluye tanto las propias cualidades de los productos (textura, tamaño, materiales, entre otros) como en el punto de venta. El sentido del tacto ha cobrado mucha importancia y significado en los últimos años en el mundo empresarial.

El sentido gustativo ayuda a despertar a los otros sentidos para crear una imagen de marca. Junto con la vista y el olfato, son capaces de evocar en la mente del consumidor la cultura y la tradición del lugar y la experiencia vivida en ese momento.

\subsection{La percepción de los sistemas sensoriales}

La percepción se puede considerar como la capacidad de los organismos para obtener información sobre su ambiente a partir de los efectos que los estímulos producen sobre los sistemas sensoriales, lo cual les permite interaccionar adecuadamente con su ambiente [9].

\subsection{Proceso del cerebro en el sistema visual}

El autor [10] en su libro de neuromarketing menciona que, el sistema visual es un sentido importante ya que este ocupa la cuarta parte del cerebro. Las funciones del sistema visual son las de interpretar y procesar imágenes visuales.

Las imágenes relativamente no se interpretan por la vista sino por el comportamiento cerebral frente a estímulos visuales.

Para la interpretación de imágenes se da un proceso principalmente en los ojos, este consiste en que la vista recibe iluminación de imágenes estos llegan a la retina, considerando que la información primero inicia en la córnea, que está cerca de tres cuartos del enfoque y la lente o cristalino que se encarga de enfocar las imágenes. 


\subsection{Proceso del sistema auditivo}

Menciona que en la cóclea hay aproximadamente 16.000 células ciliadas que se especializan en la detección de sonidos. Dichas células 'bailan' al ritmo de los sonidos con movimientos complejos, activando un numero aun mayor de neuronas que llevan la información sonora por separado hacia el hemisferio cerebral [11].

El autor [12] señala que la música ambiental puede usarse para influir en el comportamiento del consumidor deriva de un concepto atmosférico. Dadas unas alternativas, las personas prefieren entornos donde la atmosfera sea placentera y en donde asocien el sentimiento de aceptación y bienvenida. En ciertas situaciones, el ambiente puede resultar más influyente en el proceso de compra que el propio producto o la marca. Asimismo, puede influir en la formación de actitudes, recomendaciones y fidelidades.

\subsection{Percepción de la calidad de servicio}

El servicio es una forma de expresar la idea que la organización tiene respecto a la manera como se propone resolver ciertos tipos de problemas de sus clientes de una manera determinada, considerando la calidad de servicio de la empresa y la satisfacción del consumidor [13].

El modelo de la calidad de servicio fue elaborado en el año 1988, por Zeithaml, Parasuraman y Berry. Este modelo es una técnica de investigación comercial, que permite analizar la medición de la calidad del servicio. El propósito de este modelo es mejorar la calidad de servicio ofrecida por una organización. El modelo de la calidad de servicio mide lo que el cliente espera de la organización que presta el servicio. De esta forma contrasta esa medición con la estimación de lo que el cliente percibe de ese servicio [14].

\subsection{Marketing turístico}

En 'el sector turístico se cree a menudo y sin dudarlo que el marketing y las ventas son lo mismo. El departamento de ventas es uno de los más visibles en el hotel. Los directores de ventas ofrecen a los futuros clientes visitas guiadas y los invitan a los restaurantes, tiendas y bares del hotel' [15].

\subsection{Hoteles de segunda categoría en la ciudad de Riobamba}

Los hoteles considerados de segunda categoría son aquellos que tienen tres estrellas, los mismo que ponen mayor énfasis en la comodidad, estilo y servicio personalizado. La mayoría de estos tienen restaurante, piscina, gimnasio, un bar de bebidas, sala de 
juntas, sala de conferencias. Las habitaciones incluyen más servicios y la atención es más cuidadosa a la calidad y comodidad. Un hotel de tres estrellas entonces es ideal para quienes hagan turismo o por asuntos de negocios [16].

\subsection{Neuromarketing}

Es la aplicación de los estudios realizados al sistema nervioso, conocidos como neurociencias, a la disciplina del marketing. Permite conocer respuestas químicas de las personas en su rol de consumidores [17].

En el neuromarketing se pueden utilizar quipos biométricos [18] menciona que 'el electroencefalograma es una de las técnicas de las neurociencias que el neuromarketing utiliza con mayor frecuencia, específicamente por su reducido coste frente a los sistemas de imagen cerebral'. La actividad coordina de miles de neuronas produce diferencias de potencial en el cuero cabelludo que pueden ser registradas utilizando electrodos repartidos por la cabeza se puede hacer una idea de en qué zonas de nuestro cerebro se está produciendo mayor actividad.

Asi mismo existe un equipo denominado EyeTracking, consiste en un conjunto de tecnologías que permiten monitorear y registrar la forma en que una persona mira una determinada escena o imagen en la pantalla, en concreto permite determinar en qué áreas fija su atención, durante cuánto tiempo y que orden sigue en su exploración visual [19].

Los estímulos se presentan por medio de 'cualquier agente externo, estado, o cambio que puede influir en la actividad de una célula, u organismo'. Generalmente, en los estudios de condición nerviosa clínicos se aplica un estímulo eléctrico al nervio o musculo. El estímulo eléctrico se puede describir en términos absolutos o en relación con el potencial evocado del nervio o musculo [20].

\section{Metodología}

\subsection{Materiales y métodos}

La investigación se dio desde un enfoque cuali-cuantitativo, que permitió recolectar información sobre la situación particular del marketing sensorial en el Hotel el Libertador. Se investigó las percepciones y experiencias de los turistas que visitan la empresa hotelera, mediante el estímulo de sus sistemas representacionales, proporcionando información en relación a los sentidos. Se utilizó como instrumento la encuesta enfocada al marketing sensorial y las percepciones dentro de las instalaciones del hotel.

El universo se obtuvo del número de personas por destino que visitan a la provincia de Chimborazo en el cantón Riobamba, la información se consiguió del boletín turístico 
del Ministerio de Turismo; y del nivel de ocupación en hoteles de segunda categoría en la ciudad de Riobamba en el año 2018 y se aplicó a una muestra de 381 personas.

Se utilizó un Electroencefalograma Emotiv (Mind Wave Mobile 2), que permitió procesar señales eléctricas en diferentes puntos del cerebro siendo esta tecnología no invasiva, proporcionando como resultado niveles de atención, meditación y parpadeo.

La investigación es de tipo correlacional puesto que se analiza las variables de estudio para identificar si existe relación entre las mismas. Las variables de estudio se desprenden de los tres tipos de percepción visual, auditiva y kinestésica con la variable de calificación de la calidad del servicio que brinda el Hotel el Libertador.

\section{Resultados y Discusión}

Se presentan los resultados de la encuesta en cuanto a las percepciones visual, auditiva y kinestésica:

\subsection{PERCEPCIÓN VISUAL Señalética.}

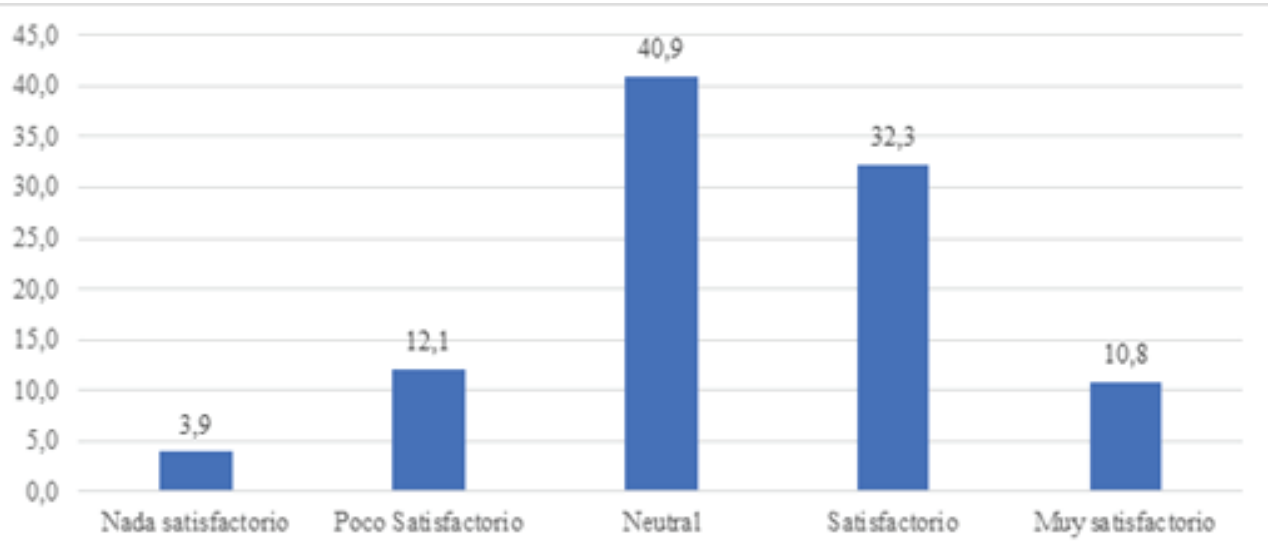

Figure 1

Señalética.

La señalética en el hotel se observa que el 40,9\% tiene una opinión neutral considerando que no es relevante, el 32,3\% del total de los encuestados tiene una opinión satisfacción acerca de la señalética y el $16 \%$ acumulado menciona que es poco y nada satisfactorio la señalética.

La señalética en un establecimiento es importante porque forma parte de la comunicación entre el servicio y el consumidor generando una experiencia de compra. 


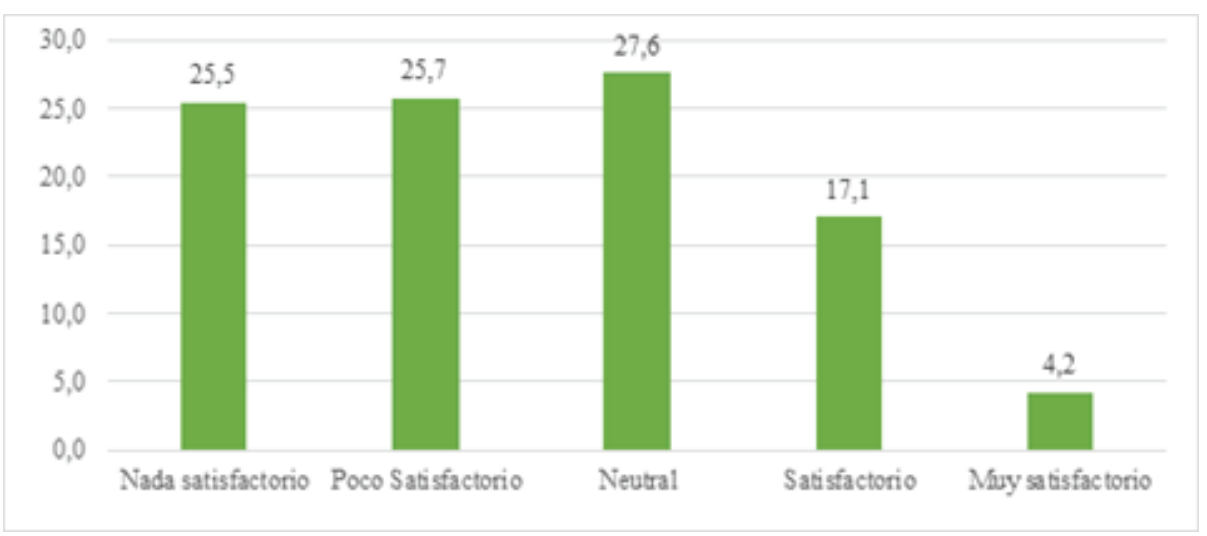

Figure 2

Vestimenta personal.

\subsection{Vestimenta del personal}

Acerca de la vestimenta del personal, el 27,6\% tiene una opinión neutral considerándose que no es relevante para quienes visitan el hotel, el 51,2\% del total de los encuestados tienen una opinión poco y nada satisfactorio. La vestimenta del personal es un tema importante porque refleja la imagen de la institución proyectando seguridad, confianza, identidad y seriedad.

\subsection{Percepción auditiva}

\section{Música en las instalaciones (ambientación)}

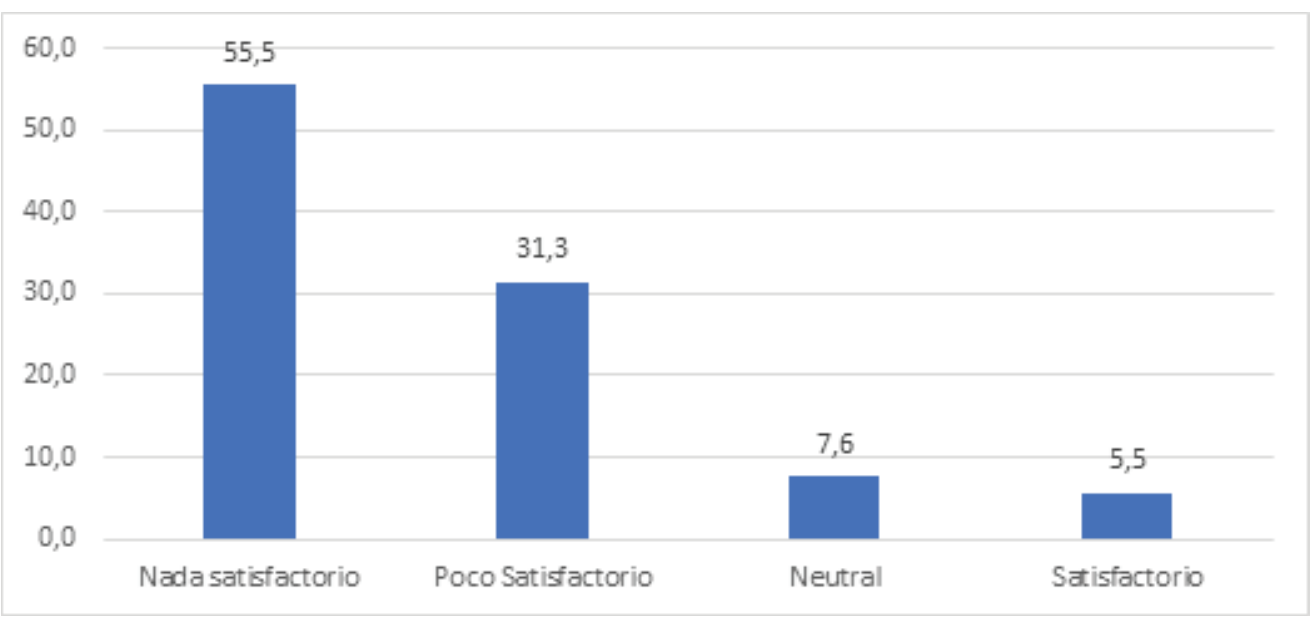

Figure 3

Música instalaciones. 
En la percepción auditiva el 55,5\% tiene una opinión de nada satisfactorio porque el hotel no cuenta con ambientación musical en las instalaciones, el 86,8\% tiene una opinión neutral y satisfactorio. La música cambia la experiencia de compra y forma parte de la decisión de compra, fidelidad y retorno al establecimiento, en el caso de estudio el hotel no cuenta con música ambiental en las instalaciones.

\subsection{Percepción kinestésica}

\section{Bienvenida a las instalaciones por recepción}

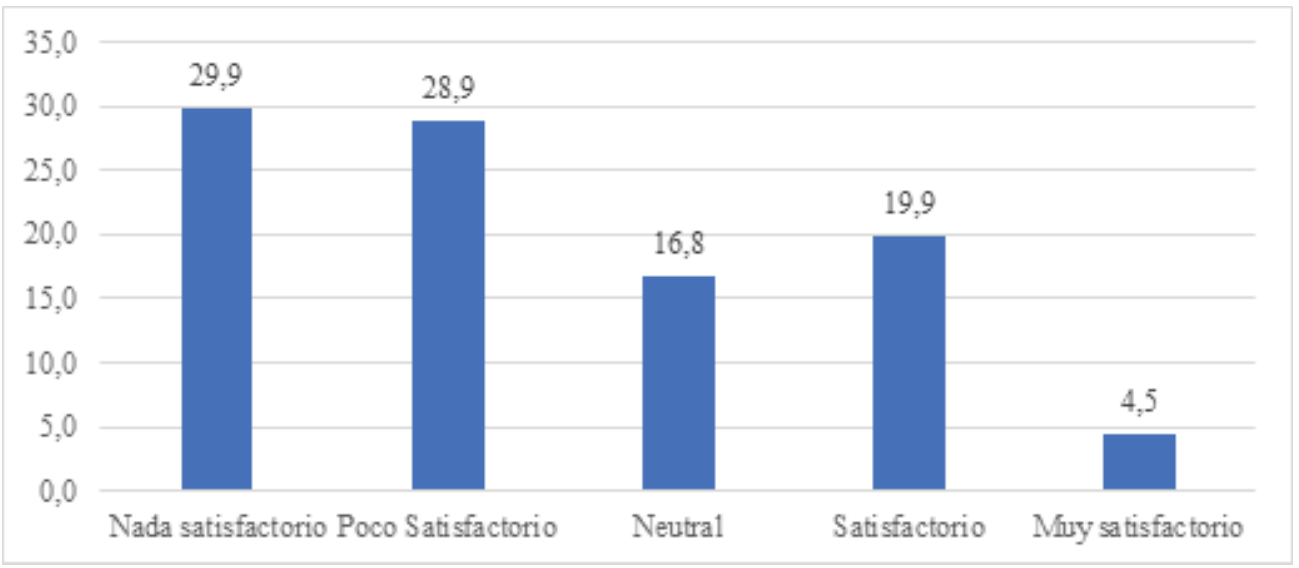

Figure 4

Bienvenida a las instalaciones.

Acerca de la bienvenida a las instalaciones del hotel, el 58,8\% del total de encuestados tienen una opinión de poco y nada satisfactorio ya que quienes son encargados de la recepción del hotel no dan la bienvenida a los visitantes, únicamente ofrecen el servicio que brindan, el 19,9\% tiene una opinión de satisfactorio ya que la atención al cliente es moderada. La amabilidad refleja la predisposición de una imagen de interés en el cliente.

\subsection{Análisis de percepciones con EEG electroencefalograma Neu- rosky}

Se realizó un estudio en las instalaciones del hotel con el equipo sensorial MindWave Mobile 2, con la colaboración de un sujeto de estudio, con el objetivo de identificar sus niveles de atención, meditación y parpadeo de los elementos de las instalaciones. 


\subsection{Percepción visual de las instalaciones con Electroencefalo- grama}

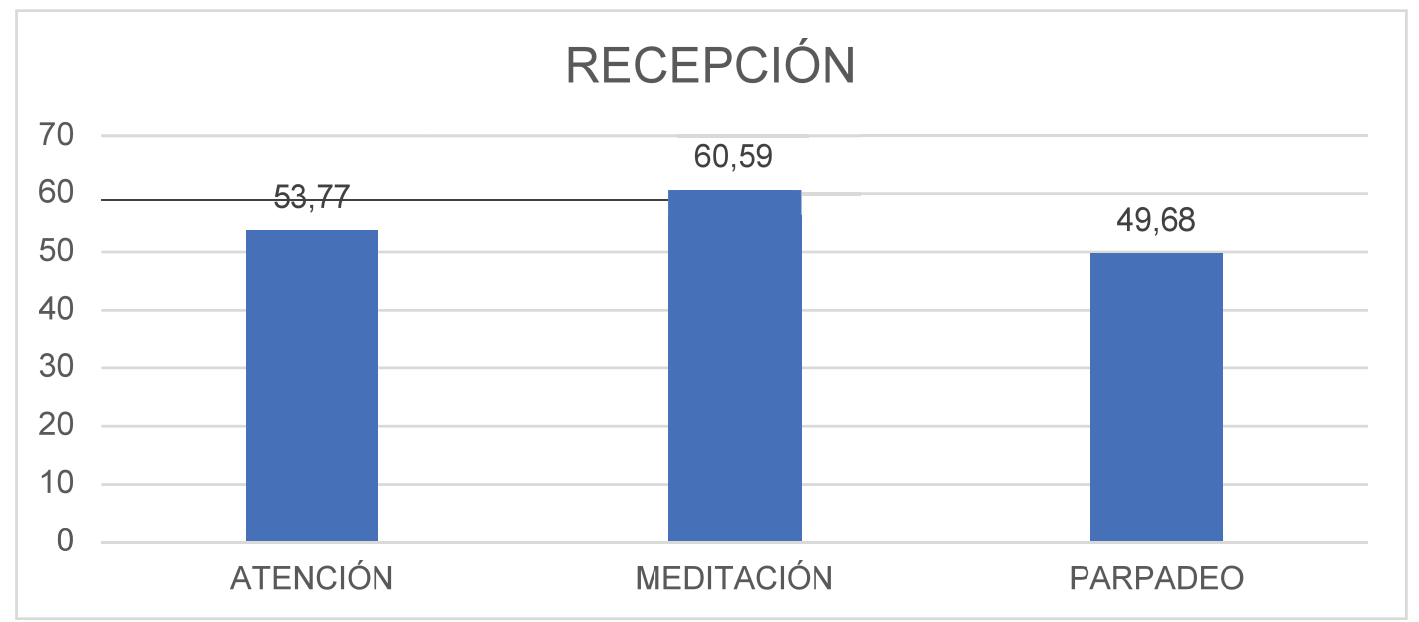

Figure 5

Análisis recepción EEG.

Con la utilización del equipo sensorial MindWave Mobile 2 se estudió los elementos de recepción, los niveles de meditación son altos 60,59\% presentando en el individuo niveles altos de tranquilidad y armonía, relajación y confianza. En el recorrido por el área de recepción del hotel, se encontró resultados del electroencefalograma en el sujeto de estudio el 60,59\% de meditación/calma mental, el 53,77\% niveles de atención y $49,68 \%$ niveles de parpadeo.

\subsection{Percepción visual de pasillos con electroencefalograma}

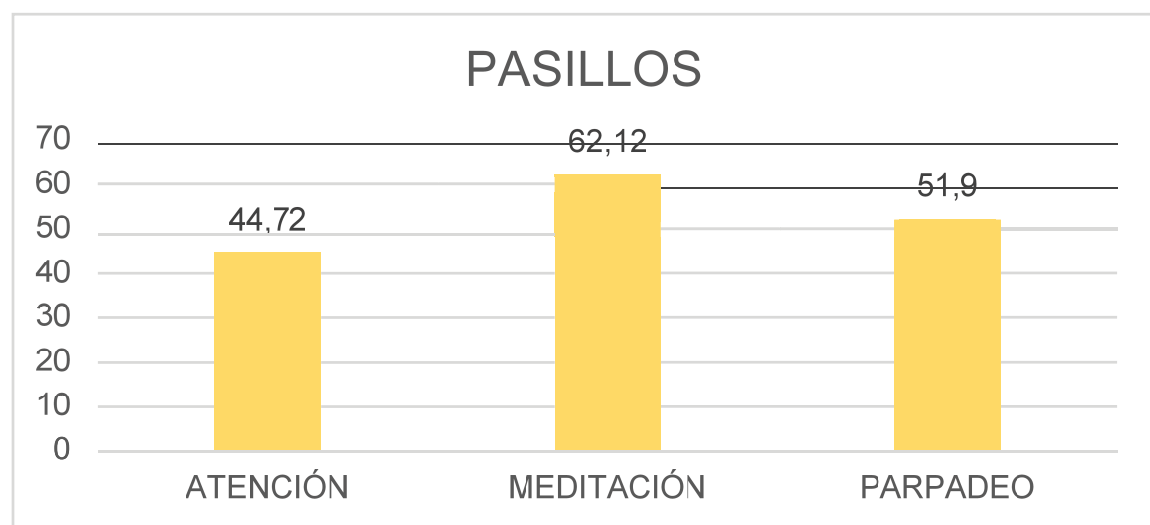

Figure 6

Análisis decoración pasillos EEG. 
En el recorrido visual por la decoración de las instalaciones (pasillos), se encontró resultados del electroencefalograma en el sujeto de estudio el 62,12\% de meditación/calma mental, es decir niveles de pensamientos o recuerdos, el 51,9\% niveles de parpadeo su atención iba disminuyendo y $44,72 \%$ en nivel de atención de los elementos que forman parte de la decoración del hotel.

\subsection{Percepción visual de habitaciones con electroencefalograma}

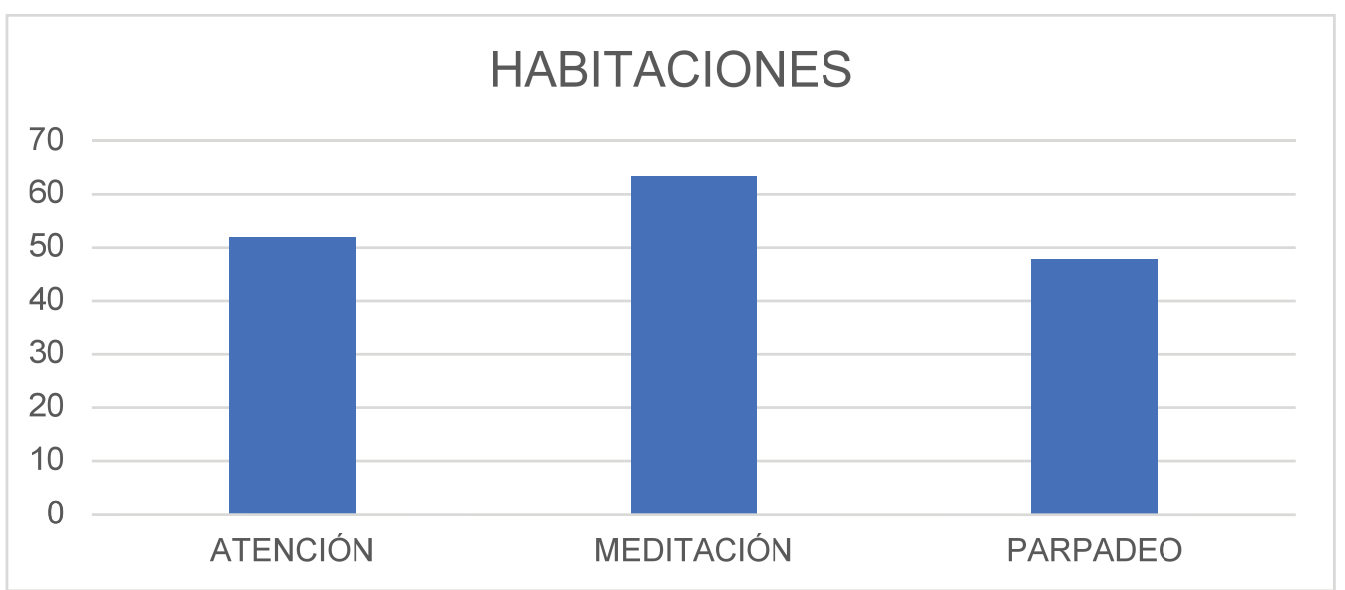

Figure 7

Análisis habitaciones EEG.

Con el equipo sensorial Mind Wave Mobile 2 se obtuvo altos niveles de meditación en el sujeto de estudio con $63,34 \%$ es decir genera en el individuo tranquilidad confianza y calma mental encontrarse en la habitación, el 51,79\% en niveles de atención. La utilización de estos métodos concluye que la estadía en las habitaciones genera niveles de tranquilidad, relajación satisfaciendo la necesidad de descanso en los turistas.

En el recorrido visual de una habitación del hotel, se encontró resultados del electroencefalograma en el sujeto de estudio el 63,34\% niveles de meditación/calma mental, el 51,79\% niveles de atención a los elementos de la habitación y $47,79 \%$ en parpadeo reduciendo su atención.

\subsection{Análisis de aromas con Electroencefalograma}

En el estudio de aromas mediante el electroencefalograma de un punto se consideró aromas que están directamente establecidas para la ambientación de establecimientos hoteleros, se tomó 4 aromas: Vainilla, naranja, flor de bergamota y canela. 
Para este estudio se procedió a realizar una experimentación con EEG y 4 aceites esenciales por un lapso de 10 segundos con intervalos de 5 segundos entre aromas y se obtuvieron los siguientes resultados:

\section{Table 2}

Resultados aroma Hotel el Libertador EEG.

\begin{tabular}{l|ll} 
AROMAS & ATENCIÓN & MEDITACIÓN \\
Vainilla & 54,73 & 58,01 \\
Naranja & 40,92 & 57,21 \\
Bergamota & 38,12 & 53,40 \\
Canela & 44,35 & 55,59
\end{tabular}

Fuente: Investigación de campo.

Se encontraron niveles altos de atención en el aroma a vainilla con el 54,73\% de atención, el segundo aroma es canela con 44,35\%, el tercer aroma es de naranja $40,92 \%$ y el cuarto de flor de bergamota con $38,12 \%$.

En los niveles de meditación/calma mental el 58,01\% es del aroma a vainilla, el 57,21\% aroma a naranja, el 55,59\% aroma a canela y el 53,40\% aroma a flor de bergamota.

Descripción del aroma a Vainilla: Su nombre científico es vainilla planifolia originaria de México, desde los años 90, el Boom del uso de la vainilla ya sea en forma de perfume o como ambientador ha aumentado con los años. La cualidad calmante de su aroma cuando se presenta un problema, estrés o existe ansiedad. Según un estudio realizado por especialistas de la Universidad de Tubingen, en Alemania, la razón de su efecto calmante es porque logra evocar de forma inconsciente emociones positivas de la infancia y que se alojan en la memoria porque tiene recuerdos con el pecho materno. Se ha considerado que este aroma es el más agradable porque es una esencia que estimula la producción de endorfinas.

\subsection{Correlación de variables}

El coeficiente de correlación permite identificar si existe relación entre dos variables estadísticas significativas de un estudio.

Tomando como referencia un valor de significancia del 0,05 se observa que las variables: Colores, decoración, iluminación y habitaciones si son significativas con un valor $\mathrm{p}$ asociado menor a esta significancia, por lo que se rechaza $\mathrm{Ho}$ y se toma $\mathrm{Ha}$, es decir la calificación de los elementos de percepción visual si está relacionada con la calidad de servicio brindado en el hotel, esta relación es directamente proporcional porque el estadístico de prueba es positivo. 
Table 3

Estadístico de prueba visual.

\begin{tabular}{|c|c|c|}
\hline & & $\begin{array}{l}\text { Califique la calidad del servicio } \\
\text { brindado del Hotel el Libertador }\end{array}$ \\
\hline \multirow[t]{3}{*}{ Colores utilizados en las paredes } & Coeficiente de correlación & $0,172^{* *}$ \\
\hline & Sig. (bilateral) & 0,001 \\
\hline & $N$ & 381 \\
\hline \multirow[t]{3}{*}{ Decoración de las instalaciones } & Coeficiente de correlación & $0,270 * *$ \\
\hline & Sig. (bilateral) & 0,000 \\
\hline & $N$ & 381 \\
\hline \multirow[t]{3}{*}{ Iluminación } & Coeficiente de correlación & $0,260^{* *}$ \\
\hline & Sig. (bilateral) & 0,000 \\
\hline & $N$ & 381 \\
\hline \multirow[t]{3}{*}{ Habitaciones } & Coeficiente de correlación & $0,118^{*}$ \\
\hline & Sig. (bilateral) & 0,022 \\
\hline & $N$ & 381 \\
\hline
\end{tabular}

Fuente: Investigación de campo.

En la decoración de las habitaciones existe una correlación, con la calificación de la calidad del servicio y sin embargo es el mayor porcentaje entre las 4 variables de la percepción visual, en la cual se puede trabajar en estrategias.

Table 4

Estadístico de prueba auditiva.

\begin{tabular}{|c|c|c|}
\hline & & $\begin{array}{l}\text { Califique la calidad del servicio } \\
\text { brindado del Hotel el Libertador }\end{array}$ \\
\hline \multirow{3}{*}{$\begin{array}{l}\text { Música en las instalaciones } \\
\text { (ambientación) }\end{array}$} & Coeficiente de correlación & 0,097 \\
\hline & Sig. (bilateral) & 0,059 \\
\hline & $N$ & 381 \\
\hline \multirow[t]{3}{*}{ Ruido en las habitaciones (Interno) } & Coeficiente de correlación & 0,048 \\
\hline & Sig. (bilateral) & 0,346 \\
\hline & $N$ & 381 \\
\hline \multirow{3}{*}{$\begin{array}{l}\text { Ruido en los exteriores del } \\
\text { establecimiento }\end{array}$} & Coeficiente de correlación & $-0,038$ \\
\hline & Sig. (bilateral) & 0,454 \\
\hline & $N$ & 381 \\
\hline \multirow{3}{*}{$\begin{array}{l}\text { Áreas de lectura con música } \\
\text { cálida }\end{array}$} & Coeficiente de correlación & 0,010 \\
\hline & Sig. (bilateral) & 0,842 \\
\hline & $N$ & 381 \\
\hline
\end{tabular}

Fuente: Investigación de campo. 
De los elementos de marketing sensorial que se ha utilizado para el estudio estadístico ninguno es significativo no se rechaza $\mathrm{Ho}$, es decir estos elementos no tienen relación con la calificación final de la calidad de servicio del hotel. Ninguna de las variables de la percepción auditiva ha sido utilizadas en el hotel, pero la que se acerca al criterio de significancia es la variable de música en las instalaciones, para estrategias de marketing sensorial se debe enfocar en esta variable.

\section{Table 5}

Estadístico de prueba kinestésica.

\begin{tabular}{|c|c|c|}
\hline & & $\begin{array}{l}\text { Califique la calidad del servicio } \\
\text { brindado del Hotel el Libertador }\end{array}$ \\
\hline \multirow{3}{*}{$\begin{array}{l}\text { Bienvenida a las instalaciones por } \\
\text { recepción }\end{array}$} & Coeficiente de correlación & $0,227^{* *}$ \\
\hline & Sig. (bilateral) & 0,000 \\
\hline & $N$ & 381 \\
\hline \multirow[t]{3}{*}{ Temperatura de las habitaciones } & Coeficiente de correlación & $0,180^{* *}$ \\
\hline & Sig. (bilateral) & 0,000 \\
\hline & $N$ & 381 \\
\hline \multirow[t]{3}{*}{ Aroma en recepción } & Coeficiente de correlación & $0,218^{* *}$ \\
\hline & Sig. (bilateral) & 0,000 \\
\hline & $N$ & 381 \\
\hline \multirow[t]{3}{*}{ Aroma en las instalaciones } & Coeficiente de correlación & $0,196^{* *}$ \\
\hline & Sig. (bilateral) & 0,000 \\
\hline & $N$ & 381 \\
\hline
\end{tabular}

Fuente: Investigación de campo.

Tomando como referencia un valor de significancia del 0,05 se observa que las variables: bienvenida a las instalaciones por recepción, temperatura de las habitaciones, aroma en recepción y aroma en las instalaciones si son significativas con un valor $p$ asociado menor a esta significancia, por lo que se rechaza Ho y se toma $\mathrm{Ha}$, es decir la calificación de los elementos de la percepción auditiva si está relacionada con la calidad de servicio brindado en el hotel

De las variables analizadas en el estudio estadístico se ha determinado que de las 4 variables de la percepción kinestésica se puede trabajar en 3 en las estrategias: bienvenida a las instalaciones por recepción, aroma en recepción y aroma en las instalaciones.

\subsection{Discusión}

En los elementos de la percepción visual en los que se debe prestar mayor atención para mejorar la percepción de la calidad del servicio es en la vestimenta del personal 
con $\mathbf{2 7 , 6 \%}$ y la señalética con $\mathbf{4 0 , 9 \%}$ ya que tienen una calificación neutral. El hotel no ha implementado una adecuada imagen corporativa, el personal no cuenta con vestimenta apropiada para realizar las actividades internas del hotel.

Los elementos de la percepción auditiva del hotel tienen una baja calificación porque el hotel no ha implementado elementos de marketing sensorial auditivo en este caso la música para ambientar las diferentes áreas de las instalaciones (área de música cálida), resultando para los turistas nada satisfactorio entre $\mathbf{5 5 , 4 \%}$ y $\mathbf{5 6 , 4 \%}$, en los ruidos internos y externos del hotel son poco satisfactorios para los turistas con $34,9 \%$ interrumpiendo un descanso satisfactorio. La ambientación musical permitirá al cliente mantener estados de relajación y tranquilidad dentro del hotel.

La percepción kinestésica (olfato, gusto y tacto) tiene una calificación de satisfactorio 3 de 7 de los elementos como; la temperatura, humedad y la funcionalidad de las habitaciones, tienen una ponderación que va de $\mathbf{3 8 , 3 \%}$ a $\mathbf{4 6 , 7 \%}$. son elementos de las instalaciones que deben perfeccionarse para influir en la calidad de servicio.

Por otro lado, 4 de los 7 elementos de la percepción kinestésica (olfato) no han sido atendidos, es el caso del aroma en diferentes áreas del hotel (recepción, instalaciones, habitaciones y SSHH) dando una percepción negativa del servicio, la correcta aplicación de aromas va a generar por parte del cliente fidelidad y lealtad, mejorando la calidad del servicio.

\section{Conclusión}

La ambientación de un punto de venta puede crear experiencias en el consumidor a través de los sentidos diferente y única. Mejora la percepción del cliente aumentando la comunicación a través del aprendizaje, con un enfoque de Sinestesia los sentidos se activan produciendo un impacto en el turista, mejorará la percepción de la calidad de servicio. El estudio realizado determino áreas de interés específicas que tienen elementos básicos dentro de las instalaciones del establecimiento hotelero, en donde deberían trabajarse acciones estratégicas en aspectos visuales, auditivos y kinestésicos.

Las estrategias de marketing sensorial en las instalaciones permitirán mejorar el ambiente del punto de venta, creando experiencias agradables en los turistas mejorando la comunicación y percepción de la calidad de servicio.

\section{References}

[1] Casado A, Sellers R. Introducción al Markting Teoría y Práctica.

[2] Cordobés J. El marketing sensrosial en la actualidad: Análisis de compañias. España: Segovia; 2015. 
[3] Manzano R, Gavilán D, Avello M, Abril C, Serra T. Marketing sensorial comunicar con los sentidos en el punto de venta. México: PEARSON; 2012.

[4] Pacheco C, Carmona C, Zapata J. Marketing sensorial como herramienta para captar y fidelizar al cliente. Bogotá: ESIC; 2013.

[5] Morgan T. ¿Qué es el Visual Merchandising? 2016.

[6] Tejada V. Neuromarketing. Todo marketing Online. 2017;2-3.

[7] Delgado A. Desarrollo sensorial en niños De 3 Años. Arequipa: UCSM; 2015.

[8] Fernández A, Villarán A. Promoción y comercialización de productos y servicios turísticos locales. España: Nobel S.A; 2017.

[9] García J, Ristol A. Atención y Percepción. Madrid: Alianza; 1999.

[10] Braidot, N. Neuromarketing en acción. Buenos Aires: Granica S.A; 2011.

[11] Braidot, N. Neuromarketing seuroeconomía y negocios. Madrid: Madrid; 2006.

[12] Álvarez R. Fusión perfecta neuromarketing. New York: FT Perntice Hall; 2013.

[13] Koenes A. Diseño del servicio. Madrid: Díaz de Santos S.A; 2000.

[14] Aiteco Consultores desarrollo y gestión. El modelo SERVQUAL de calidad de servicio. Aiteco Consultores desarrollo y gestión. 2012;1-4.

[15] Kotler P, Bowen J, Makens J, García J, Flores J. Marketing turistico. Madrid: PEARSON; 2011.

[16] Todo sobre Riobamba. El Riobambeño. 2017 November 10. Recuperado de https: //www.riobamba.co/turismo-riobamba/

[17] Business Management. Neuromarketing: Marqueteando los deseos. Lima: BM Business Management; 2014.

[18] Díaz C. Marketing Olfativo. España: Tesis Universidad de León; 2013.

[19] Ramírez A. Eye-tracking: Una técnica se seguimiento de la mirada. Costa Rica: ECR; 2012.

[20] Rothstein J, Roy S, Wolf S. Manual del especialista en rehabilitación. Chicago: Paidotribo; 2005. 